\title{
Influência da remoção de plasma seminal por centrifugação na qualidade de sêmen canino resfriado
}

\author{
[Influence of seminal plasma removal by centrifugation in cooled sperm quality in dogs]
}

\section{"Artigo Científico/Scientific Article"}

\author{
Fernanda Almeida Pereira ${ }^{\mathbf{1}}$, Fernando Silva Lima ${ }^{\mathbf{1}}$, Gabrielle Bianca Alves Nascimento ${ }^{\mathbf{1}}$, \\ Luana Souza Silva ${ }^{\mathbf{1}}$, Luisa Lima Nantes Oliveira ${ }^{\mathbf{1}}$, Poliany Ferreira Marques ${ }^{\mathbf{1}}$, \\ Queren Hapuque Sousa Lima Aguiar', Fernanda Carlini Cunha Santos ${ }^{1,2 *}$
}

\author{
${ }^{1}$ Universidade Federal de Roraima, Boa Vista-RR, Brasil. \\ ${ }^{2}$ Líder do Grupo de Pesquisa do Diretório de Grupos de Pesquisa do CNPq: Repro - Reprodução Animal \\ *Autor para correspondência/Corresponding author: E-mail: carlini.fernanda@ hotmail.com
}

\section{Resumo}

Durante o resfriamento de sêmen canino, o contato do plasma seminal por longo período com os espermatozoides pode afetar negativamente a composição da membrana plasmática e reduzir a capacidade de fecundação. A centrifugação para remoção do plasma também pode ter influência negativa sobre célula espermática, devido a danos celulares físicos, remoção de fatores inibidores da capacitação e aumento na produção de radicais livres. Diante disso, o objetivo deste trabalho foi avaliar a influência da remoção de plasma seminal por centrifugação na qualidade de sêmen canino submetido a resfriamento. Foram coletados 19 ejaculados de caninos hígidos. Cada ejaculado foi avaliado quanto à qualidade espermática e dividido em dois tratamentos: 1) não-centrifugado: diluição e armazenamento sob resfriamento; 2) centrifugado: diluição, centrifugação a $600 \times$ g por 15 minutos, descarte de sobrenadante, ressuspensão do pellet com diluente e armazenamento sob resfriamento a $5^{\circ} \mathrm{C}$ por $48 \mathrm{~h}$. As amostras foram avaliadas quanto à motilidade, vigor, integridade de membrana e morfologia, às $24 \mathrm{~h}$ e $48 \mathrm{~h}$ de resfriamento. Os dados foram avaliados por estatística descritiva, ANOVA e a comparação entre médias pelo teste de Tukey. Foi verificada diferença significativa $(\mathrm{p}<0.05)$ quanto à motilidade às $24 \mathrm{~h}$ (não-centrifugado 70,2 $\pm 3,9 \%$ e centrifugado $61,9 \pm 3,3 \%$ ); às 48h $(59,5 \pm 3,9 \%$ e $47,6 \pm 4,7 \%$, respectivamente) e às 24 h quanto a defeitos espermáticos $(11,4 \pm 0,7 \%$ e $14,7 \pm 1,2 \%$, respectivamente). Como resultado, as amostras de sêmen canino não submetidas à remoção do plasma seminal por centrifugação apresentaram maior média de motilidade e morfologia normal durante o resfriamento a $5^{\circ} \mathrm{C}$ por $48 \mathrm{~h}$.

Palavras-chave: efeito mecânico; fração espermática; fração prostática; próstata; refrigerado.

\begin{abstract}
During semen cooled storage, the long-term exposure to seminal plasma can negatively influence plasma membrane composition and reduce fertilization capacity of spermatozoa. Seminal plasma removal by centrifugation can also have a negative effect in the sperm cell, due to physical damage, removal of inhibition capacitation factors and arise in free radicals' production. Therefore, the aim of this experiment was to evaluate the influence of seminal plasma removal by centrifugation in sperm quality of dog semen submitted to cooling storage. Nineteen ejaculates $(n=19)$ were collected from healthy dogs. Each ejaculate was evaluated regarding sperm quality and splitted in two treatments: 1) non-centrifugated: diluted and submitted to cooled storage; 2) centrifugated: diluted, centrifugated at $600 \times \mathrm{g}$ for 15 minutes, supernatant discarded, pellet resuspension with extender and submitted to cooled storage at $5^{\circ} \mathrm{C}$ for $48 \mathrm{~h}$. Sperm samples were evaluated regarding motility, vigor, membrane integrity and morphology at 24 and $48 \mathrm{~h}$ of cooled storage. Data was evaluated with descriptive statistic, ANOVA and comparisons between means with Tukey test. Significant difference ( $\mathrm{p}<$ 0.05 ) was observed in motility at $24 \mathrm{~h}$ (non-centrifugated $70.2 \pm 3.9 \%$ and centrifugated $61.9 \pm 3.3 \%$ ), at $48 \mathrm{~h}$ $(59.5 \pm 3.9 \%$ and $47.6 \pm 4.7 \%$, respectively) and regarding morphological defects at $24 \mathrm{~h}(11.4 \pm 0.7 \%$ and
\end{abstract}


$14.7 \pm 1.2 \%$, respectively). Canine semen samples which were not submitted to seminal plasma removal by centrifugation presented higher motility and normal morphology during cooled storage at $5^{\circ} \mathrm{C}$ for $48 \mathrm{~h}$.

Keywords: chilled; mechanical effect; prostate; sperm fraction; prostatic fraction.

\section{Introdução}

O sêmen canino é composto pela fração espermática, rica em espermatozoides, e a fração prostática, contendo plasma seminal produzido pela próstata. Durante a ejaculação, o canino emite 1) fração prostática; 2) fração espermática e 3) fração prostática, respectivamente (Johnston et al., 2001).

Durante a coleta de sêmen canino, principalmente quando o profissional ainda não está habituado a coletar aquele determinado reprodutor, frequentemente coleta-se as frações espermática e prostática juntas. Durante o resfriamento de sêmen, o contato do plasma seminal com espermatozoides por longo período pode afetar a qualidade espermática.

A composição bioquímica do fluido seminal apresenta grande variabilidade e, dentre outros fatores, resulta em resultados divergentes na literatura quando ao efeito da manutenção do plasma seminal junto com os espermatozoides (Love et al., 2010). Em caninos, England e Allen (1992) relataram que após 6 horas de incubação de sêmen a $37^{\circ} \mathrm{C}, \quad$ o percentual de células morfologicamente íntegras era maior nos tratamentos somente com a $2^{\circ}$ fração do ejaculado, quando comparado aos tratamentos adicionados da $1^{\circ}$ e $3^{\circ}$ fração. Em suínos, Kawano et al. (2004) sugeriram que o plasma seminal contém fatores que modificam o espermatozoide, sendo que a incubação dos espermatozoides com plasma antes do congelamento reduz a congelabilidade e a capacidade de penetração no oócito após descongelamento. Estudos sugerem que o plasma seminal afeta a capacidade de fertilização devido a modificações na membrana do espermatozoide, atuando por exemplo, reduzindo ou aumentando a quantidade de colesterol da membrana plasmática (Gasset et al., 2000).

Por outro lado, a centrifugação é um método físico que auxilia na remoção da maioria do plasma seminal, embora também seja controverso seu efeito sobre a qualidade da célula espermática nas diferentes espécies. Cunha e Lopes (2009) afirmaram que o uso de centrifugação para a retirada do plasma seminal não induziu efeito negativo sobre os parâmetros de qualidade espermática em caninos. Em contrapartida, a centrifugação não é considerada um procedimento totalmente inócuo à célula, podendo resultar em danos celulares físicos, remoção de fatores inibidores da capacitação e prostaglandinas (Carrell et al., 1998), assim como redução da motilidade (Sharma et al., 1997). A centrifugação também pode induzir a capacitação espermática de forma prematura e desnecessária, reduzindo o período de vida útil dos espermatozoides. Além disso, a centrifugação pode aumentar a produção de radicais livres, que causam alterações nas funções da membrana, induzindo a peroxidação lipídica (Prakash et al., 1998). Também é importante lembrar que durante a centrifugação e ressuspensão do pellet, um percentual de células será perdido, reduzindo a concentração total de espermatozoides.

A qualidade espermática em equinos pode ser afetada tanto pelo contato prolongado dos espermatozoides com o plasma seminal, o que ocorre em ejaculados somente adicionados de diluente e criopreservados (Jasko et al., 1992; Monteiro et al., 2019), quanto pela centrifugação para remoção de plasma (Sieme et al., 2003), o que ocorre em ejaculados centrifugados, resuspendidos em diluente e resfriados. No entanto, a retirada total do plasma também não é recomendada, considerando que este fluido exerce funções sobre o metabolismo espermático e processo de fecundação, como: ativação da motilidade, ação antimicrobiana, neutralização dos metabólitos espermáticos, proteção contra a acrosina por meio de inibidores de proteases e mediador da capacitação espermática (Elzanaty et al., 2002; Troedsson et al., 2005).

Tanto o efeito da centrifugação como a manutenção dos espermatozoides em contato com plasma seminal são considerados controversos na literatura, podendo ambos procedimentos afetar o espermatozoide. Diante disso, o objetivo deste experimento foi avaliar a influência da remoção de plasma seminal por centrifugação na qualidade de sêmen canino submetido a resfriamento por 48 horas a $5^{\circ} \mathrm{C}$.

\section{Material e Métodos}

Foram coletados 19 ejaculados $(n=19)$, provenientes de 10 caninos hígidos, de múltiplas raças, adultos (acima de 2 anos de idade), 
residentes em Boa Vista, Roraima. Todos os animais eram alimentados com ração comercial, duas vezes ao dia. Cada animal foi coletado duas vezes com intervalo mínimo de uma semana, exceto um que foi coletado somente uma vez.

Os ejaculados foram coletados pela técnica de manipulação digital (Johnston et al., 2001), incluindo primeira e segunda fração. Imediatamente após a coleta de cada indivíduo, o sêmen foi avaliado quanto aos critérios macroscópicos, incluindo coloração, odor, aspecto e volume; e microscópicos, incluindo concentração, motilidade, vigor, integridade de membrana plasmática e morfologia, em microscópio ótico (BX 41 Olympus América, Inc, São Paulo, SP, Brasil), de forma subjetiva. A metodologia empregada foi de acordo com a descrita pelo Colégio Brasileiro de Reprodução Animal (CBRA, 2013). As amostras foram analisadas sempre pelo mesmo avaliador.

A contagem das células espermáticas foi realizada com auxílio de câmara de Neubauer, após diluição de $10 \mu \mathrm{L}$ de sêmen em $190 \mu \mathrm{L}$ de água. Uma alíquota de $10 \mu \mathrm{L}$ de sêmen foi colocada em uma lâmina e recoberta por lamínula e aquecidas para avaliação de motilidade (0-100\%) e vigor (15). Para realização do teste hiposmótico, que investiga a integridade de membrana, $10 \mu \mathrm{L}$ de sêmen foi adicionado de $20 \mu \mathrm{L}$ de água destilada e incubado a $37^{\circ} \mathrm{C}$ em banho-maria por 20 minutos. Após este período, 100 células foram classificadas com membrana funcional (cauda enrolada) e membrana afuncional (cauda reta). As alterações morfológicas foram avaliadas através da adição de $10 \mu \mathrm{L}$ de eosina-nigrosina (Sigma-Aldrich ${ }^{\circledR}$ ) em $10 \mu \mathrm{L}$ de sêmen, disposto entre lâmina e lamínula, sendo contabilizadas 100 células espermáticas e classificadas quanto à defeitos maiores: peça intermediária anormal, cabeça anormal, gota citoplasmática proximal e cauda fortemente enrolada, e defeitos menores: cabeça isolada anormal, gota citoplasmática distal e cauda dobrada.

O diluente de resfriamento à base de leite desnatado (Kenney et al., 1975) foi adicionado a amostra até concentração final de $25 \times 10^{6}$ espermatozoides $/ \mathrm{mL}$. Em seguida, a amostra foi dividida em dois tratamentos (Figura 1):

1) Não-centrifugado: armazenamento sob resfriamento.

2) Centrifugado: centrifugação a $600 \times \mathrm{g}$ por 15 minutos, descarte de sobrenadante, ressuspensão do pellet com diluente de resfriamento e armazenamento sob resfriamento.

As amostras foram mantidas dentro de eppendorfs, sob resfriamento em geladeira a $5^{\circ} \mathrm{C}$. A avaliação microscópica foi realizada às $24 \mathrm{~h}$ e $48 \mathrm{~h}$ de resfriamento, após aquecimento de uma alíquota de $300 \mu \mathrm{L}$ por 5 minutos em banho-maria a $37^{\circ} \mathrm{C}$. Os parâmetros avaliados foram os mesmos descritos: motilidade, vigor, integridade de membrana plasmática e morfologia.

As variáveis foram distribuídas de acordo com teste de normalidade Shapiro-Wilk. Os dados foram avaliados por estatística descritiva, ANOVA e a comparação entre médias pelo teste de Tukey. Foi utilizado o programa computacional Statistix 9 (Statistix. Statistix 9 for Windows; Analytical Software, Tallahassee, FL). O nível de significância foi de $\mathrm{p}<0.05$.

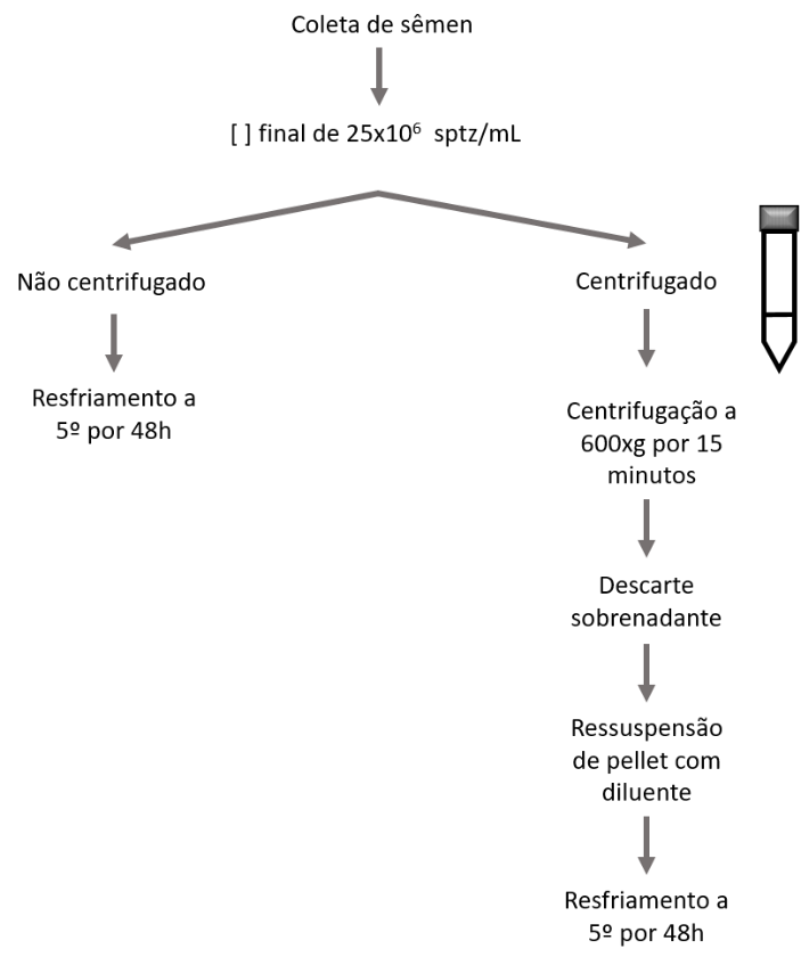

Figura 1. Representação esquemática dos tratamentos não centrifugado e centrifugado.

\section{Resultados e Discussão}

Todos os ejaculados apresentaram valores médios de qualidade espermática acima dos mínimos preconizados pelo CBRA (2013). No sêmen fresco, a média \pm erro padrão da média de concentração foi de $142 \pm 19 \times 10^{6} \mathrm{sptz} / \mathrm{mL}$; motilidade $91 \pm 1,1 \%$; vigor $2,8 \pm 0,01$; integridade de membrana $94 \pm 0,8 \%$; morfologia normal $91 \pm 1 \%$; defeitos totais $9 \pm 1 \%$; defeitos maiores $6 \pm 0,8 \%$ e defeitos menores $3 \pm 0,5 \%$.

Foi verificada diferença significativa entre 
os tratamentos quanto à motilidade às $24 \mathrm{~h}$ (nãocentrifugado $70,2 \pm 3,9 \%$ e centrifugado $61,9 \pm 3,3 \%$ ) e às $48 \mathrm{~h}$ (não-centrifugado $59,5 \pm 3,9 \%$ e centrifugado $47,6 \pm 4,7 \%$ ); e às $24 \mathrm{~h}$ quanto a defeitos espermáticos totais (não-centrifugado $11,4 \pm 0,7 \%$ e centrifugado $14,7 \pm 1,2 \%$ ) (Tabela 1 ).
Independente do tratamento, conforme aumentou o período de resfriamento, as médias de motilidade, integridade de membrana plasmática e espermatozoides com morfologia normal declinaram.

Tabela 1. Qualidade de sêmen canino $(\mathrm{n}=19)$ durante resfriamento a $5^{\circ} \mathrm{C}$ por $48 \mathrm{~h}$ conforme tratamento centrifugado e não-centrifugado (média \pm erro padrão da média).

\begin{tabular}{ccccc}
\hline Parâmetros & Não-centrif & Centrif & Não-centrif & Centrif \\
$\mathbf{2 4 h}$ & $\mathbf{2 4 h}$ & $61,9 \pm 3,3 \mathrm{~b}$ & $59,5 \pm 3,9 \mathrm{x}$ & $47,6 \pm 4,7 \mathrm{y}$ \\
\hline Motilidade & $70,2 \pm 3,9 \mathrm{a}$ & $2,8 \pm 0,1$ & $2,6 \pm 0,1$ & $2,4 \pm 0,1$ \\
Vigor & $2,8 \pm 0,1$ & $89,3 \pm 1,1$ & $86,8 \pm 1,3$ & $85,1 \pm 1,8$ \\
Hiposmótico & $91 \pm 0,8$ & $85,2 \pm 1,2$ & $84,5 \pm 0,7$ & $84,6 \pm 0,9$ \\
Morfologia & $87,6 \pm 0,8$ & $14,7 \pm 1,2 \mathrm{~b}$ & $15,4 \pm 0,7$ & $15,3 \pm 0,9$ \\
Defeitos & $11,4 \pm 0,7 \mathrm{a}$ & $9,7 \pm 1,5$ & $10,7 \pm 1$ & $9,9 \pm 1,5$ \\
D. Maior & $8 \pm 0,8$ & $5 \pm 1,1$ & $5,5 \pm 0,9$ & $5 \pm 0,7$ \\
D. Menor & $3,1 \pm 0,3$ & & \\
\hline
\end{tabular}

Centrif: amostras centrifugadas a $600 \times \mathrm{g}$ por 15 minutos, prévio ao período de resfriamento. Não-centrif = amostras não centrifugadas. D.: defeito. a,b: indicam diferença estatística entre tratamentos centrifugado e não-centrifugado as $24 \mathrm{~h}$. $\mathrm{x}, \mathrm{y}$ : indicam diferença estatística entre tratamentos centrifugado e não-centrifugado às $48 \mathrm{~h}$.

De acordo com Rota et al. (1995), o armazenamento de sêmen canino junto com fluido prostático autólogo (sem diluente) foi considerado inadequado, quando comparado ao sêmen adicionado de diluente contendo gema de ovo. Nas amostras mantidas somente com fluido prostático foi observada baixa motilidade e percentual de membrana plasmática íntegra após dois dias de resfriamento. Em equinos, a retirada total do plasma seminal de um ejaculado pode não ser benéfica à manutenção da capacidade fertilizante dos espermatozoides (Vianna et al., 2002). Durante a centrifugação convencional, sem uso de coloides ou técnicas associadas, é difícil a remoção do plasma em sua totalidade, sendo que o restante que fica em contato com sêmen não seria o suficiente para expressar efeito negativo na qualidade espermática.

Concordando com os resultados do presente estudo, Matas et al. (2007) e Castelo et al. (2010) também relataram a influência negativa do uso de centrifugação. Em suínos, Matas et al. (2007) reportaram que a atividade mecânica da centrifugação para remoção de plasma seminal pode promover danos estruturais irreversíveis aos espermatozoides, com mudanças estruturais no acrossoma e diminuição significativa da motilidade espermática. Em sêmen de catetos, Castelo et al. (2010) relataram efeito negativo da centrifugação para remoção de plasma seminal prévio ao congelamento sobre morfologia espermática, linearidade, retilinearidade e batimento de cabeça, após descongelamento.

De acordo com Treulen et al. (2012), a suplementação de diluentes de sêmen com fluido seminal auxilia na preservação de integridade de membrana plasmática, integridade de acrossoma e funcionalidade de membrana, no entanto compromete a motilidade de sêmen canino mantido refrigerado por $72 \mathrm{~h}$, sugerindo que mais estudos são necessários para entender o efeito inibidor do plasma seminal sobre a motilidade e reportar a repercussão disso sobre a fertilidade.

O contato prolongado dos espermatozoides com o plasma seminal, assim como a centrifugação para remoção de plasma, são considerados fatores que influenciam a qualidade espermática durante $o$ resfriamento. No presente trabalho, as amostras não-centrifugadas apresentaram principalmente maior média de motilidade e morfologia normal, em comparação as centrifugadas $(\mathrm{p}<0.05)$, sugerindo que não há necessidade de remoção do plasma seminal em amostras submetidas posteriormente ao resfriamento a $5^{\circ} \mathrm{C}$ por até $48 \mathrm{~h}$. Em relação aos defeitos, as amostras centrifugadas apresentaram maior percentual de cabeça anormal, cauda dobrada e cauda fortemente enrolada as $24 \mathrm{~h}$ e $48 \mathrm{~h}(\mathrm{p}>0.05)$. Este aumento nos defeitos poderia ser atribuído a danos físicos a célula espermática durante a etapa de centrifugação. Os defeitos de cauda podem ter influenciado negativamente na motilidade espermática.

A etapa de centrifugação necessita de mais 
equipamentos (centrífuga), material de laboratório e rede elétrica, consome mais tempo e é mais trabalhosa, quando comparada a manipulação de amostras sem esta etapa.

\section{Conclusão}

Diante dos resultados, foi considerado que a remoção de plasma seminal por centrifugação não é um procedimento obrigatório ou necessário para resfriamento de sêmen em caninos, pois as amostras não submetidas à remoção do plasma seminal apresentaram maior média de motilidade e células morfologicamente íntegras durante $\mathrm{o}$ resfriamento a $5^{\circ} \mathrm{C}$ por $48 \mathrm{~h}$.

\section{Conflito de Interesse}

Declaramos não existir conflitos de interesse.

\section{Comitê de Ética}

Este experimento utilizou animais como modelo experimental sendo aprovado pelo Comitê de Ética no Uso de Animais (CEUA-UFRR) sob registro 023/2018.

\section{Agradecimentos}

Este trabalho recebeu apoio financeiro do PRÓ-PESQUISA/UFRR

(Proc.

23129.010575/2020-79)

\section{Referências}

Carrell, D.T.; Kuneck, P.H.; Peterson, C.M.; Hatasaka, H.H.; Jones, K.P.; Campbell B.F. A randomized prospective analysis of five sperm preparation techniques before intrauterine insemination of husband sperm. Fertility and Sterility, 69(1): 122-126, 1998.

Castelo, T.S.; Bezerra, F.S.; Lima, G.L.; Alves, H.M.; Oliveira, I.R.; Santos E.A.; Peixoto, G.C.; Silva, A.R. Effect of centrifugation and sugar supplementation on the sêmen cryopreservation of captive collared peccaries (Tayassu tajacu). Cryobiology, 61(3): 275279, 2010.

CBRA. Colégio Brasileiro de Reprodução Animal. Manual para exame andrológico e avaliação de sêmen animal. $3^{\text {a }}$ ed. Belo Horizonte, 2013. $104 \mathrm{p}$.

Cunha, I.C.N.; Lopes, M.D. Efeito da centrifugação sobre a qualidade do sêmen canino. Arquivo Brasileiro de Medicina Veterinária e Zootecnia, 61(1): 104-109, 2009.
Elzanaty, S.; Richthoff, J.; Malm, J.; Giwercman, A. The impact of epididymal and accessory sex gland function on sperm motility. Human Reproduction, 17(11): 2904-2911, 2002.

England, G.C.W.; Allen, W.E. Factors affecting the viability of canine spermatozoa II: Effects of seminal plasma and blood. Theriogenology, 37(2): 373-381, 1992.

Gasset, M.; Magdaleno, L.; Calvete, J.J. Biophysical study of the perturbation of model membrane structure caused by seminal plasma protein PDC-109. Archives of Biochemistry and Biophysics, 374(2): 241-247, 2000.

Jasko, D.J.; Hathaway, J.A.; Schaltenbrand, V.L.; Simper, W.D.; Squires, E.L. Effect of seminal plasma and egg yolk on motion characteristics of cooled stallion spermatozoa. Theriogenology, 37(6): 1241-1252, 1992.

Johnston, S.D.; Kustritz, M.V.R.; Olson, P.N.S. Canine and feline theriogenology. $1^{\text {st }}$ ed. Philadelphia: W.B. Saunders, 2001. 592p.

Kawano, N.; Shimada, M.; Terada, T. Motility and penetration competence of frozen-thawed miniature pig spermatozoa are substantially altered by exposure to seminal plasma before freezing. Theriogenology, 61(2-3): 351-364, 2004.

Kenney, R.M.; Berman, R.V.; Cooper, W.L.; Morse, W.L. Minimal contamination techniques for breeding mares: technique and preliminary findings. Proceedings of Annual Convention American Association Equine Practioners, 21: 327-36, 1975.

Love, C.C.; Thompson, J.A.; Brinsko, S.P. et al. Effect of inter-stallion seminal plasma variability on motility, viability, and DNA integrity of cauda epididymal sperm. Animal Reproduction Science, 121: 191, 2010.

Matas, C.; Decuadro, G.; Martínez-Miró, S.; Gadea, J. Evaluation of a cushioned method for centrifugation and processing for freezing boar semen. Theriogenology, 67(5): 10871091, 2007.

Monteiro, G.A.; Ramires Neto, C.; Sancler-Silva, Y.F.R.; Oliveira, L.Z.; Aqua, C.P.F.D.; Hartwig, F.P.; Papa, P.M.; Pantoja, J.; Silva, D.F.; Papa, F.O. Efeito da adição de plasma seminal oriundo de animais de alta e baixa fertilidade na criopreservação de espermatozoides da cauda do epidídimo e do ejaculado de garanhões subférteis. Arquivo Brasileiro de Medicina Veterinária e Zootecnia, 71(3): 752-760, 2019. 
Prakash, P.; Leykin, L.; Chen, Z.; Toth, T.; Sayegh, R.; Schiff, I.; Isaacson, K. Preparation by differential gradient centrifugation is better than swim-up in selecting sperm with normal morphology (strict criteria). Fertility and Sterility, 69(4): 722-734, 1998.

Rota, A.; Ström, B.; Linde-Forsberg, C. Effects of seminal plasma and three extenders on canine semen stored at $4^{\circ} \mathrm{C}$. Theriogenology, 44(6): 885-900, 1995.

Sharma, R.K.; Vemulapalli, S.; Kohn, S.; Agarwal, A. Effect of centrifuge speed, refrigeration medium, and sperm washing medium on cryopreserved sperm quality after thawing. Archives of Andrology, 39(1): 33-38, 1997.

Sieme, H.; Martinsson, G.; Rauterberg, H.; Walter, K.; Aurich, C.; Petzold, R.; Klug, E. Application of techniques for sperm selection in fresh and frozen-thawed stallion semen. Reproduction in Domestic Animals, 38(2): 134-140, 2003.
Vianna, S.A.B.; Souza, G.V.; Fagundes, B.; Fonseca, C.W.; Maeda, M.; Guimarães, M.C.; Matta, M.F.R.; Matta, G.G.F.; Tilburg, M.F.; Silva, J.F.S. Influência do plasma seminal na congelabilidade de sêmen equino. Revista Brasileira de Reprodução Animal, 26(0): 179-181, 2002.

Treulen, F.; Sánchez, R.; Risopatrón, J. Effects of seminal fluid fractions on plasma and acrosome membrane integrity and mitochondrial membrane potential determined by flow cytometry in chilled canine spermatozoa. Reproduction in Domestic Animals, 47(6): 1043-1048, 2012.

Troedsson, M.H.T.; Desvousges, A.S.; Alghamdi, A.S.; Dahms, B.; Dow, C.A.; Hayna, J.; Valesco, R.; Collahan, P.T.; Macpherson, M.L.; Pozor, M., Buhi, W.C. Components in seminal plasma regulating sperm transport and elimination. Animal Reproduction Science, 89(1-4): 171-186, 2005. 